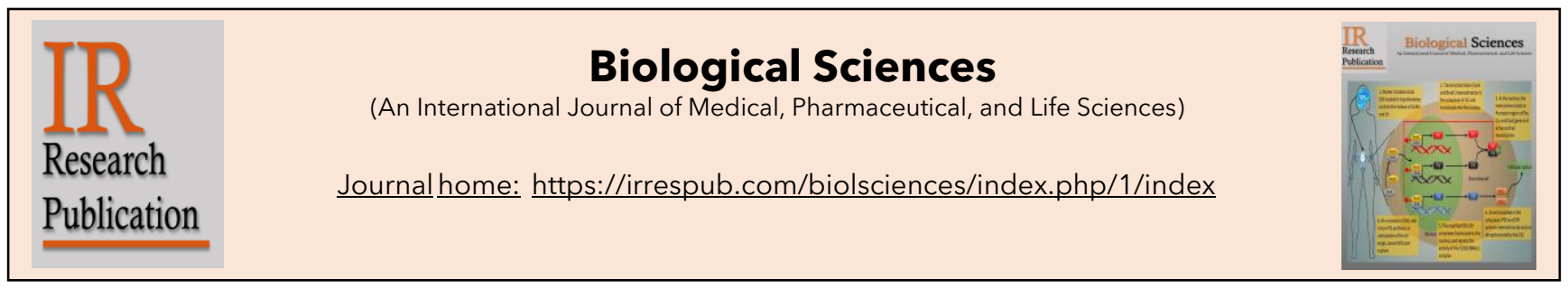

\title{
Need of toxicity studies for cosmetic products and their approaches
}

\author{
Gaurav Mishra*, Saloni Rahi \\ ISF College of Pharmacy, GT Road, Ghal Kalan, Moga - 142001 (Punjab), India.
}

\author{
ARTICLE HISTORY \\ Received: 02-01-2022 \\ Revised: 12-01-2022 \\ Accepted: 14-01-2022 \\ Online: 17-01-2022 \\ KEYWORDS \\ Cosmetic products \\ Toxicity studies \\ Chemicals \\ Health issues \\ Approaches
}

\section{ABSTRACT}

The present attempt is focused on the need for toxicity studies of cosmetic products and their different approaches. The use of chemicals obtained from different sources has been increased significantly. These chemicals utilized for the preparation of the cosmetic applied to the human body for different purposes like cleansing, beautifying, etc, have toxic effects on the body. These may also lead to serious health issues. To combat this expulsive issue of toxicity, various toxicity studies are performed. With the help of toxicity study on cosmetic products, the biological information required for the estimation of toxic adverse effects of the cosmetics produced after human exposure can be obtained. Altogether, the current mini-review gives a descriptive note on the need and different approaches for toxicity studies of cosmetic products.

\section{Introduction}

Before 1938, the concept of cosmetics was different, cosmetology was regarded as the style of selling dreams rather than objective, efficacy and regulation of cosmetics was not under drugs. Sometimes safety for the consumers was also problematic. Later cosmetics was regulated through the federal food and drug cosmetic act (FD\&C) by the United States Food and Drug Administration (US FDA) (1). US FD\&C Act 1940, 201(i) has defined cosmetics as "articles intended to be rubbed, poured, sprinkled, or sprayed on, introduced into, or otherwise applied

*Address for correspondence

ISF College of Pharmacy, GT Road, Ghal Kalan, Moga - 142001 (Punjab), India.

Email: mgaurav3807@gmail.com

DOI: https://doi.org/10.55006/biolsciences.2022.0201

Published by IR Research Publication; Mishra G et al (C) 2022 by Biological Sciences is licensed under CC BY 4.0 (c) to the human body for cleansing, beautifying, promoting attractiveness, or altering the appearance". US FDA also states that cosmetic products should contain generally regarded as safe ingredients i.e., they should not contain harmful substances (2). The role of chemicals in modern nations has expanded significantly in the second half of this century. In the present world economy, all sorts of industrial production utilize the chemicals obtained either from natural sources (e.g., plants, animals and microorganisms) or through the synthetic process (3). These chemicals are toxic to the human body. Preservatives and fragrances used in cosmetics are also toxic and can cause cancer, mutation, reproductive toxicity and endocrine disruption. Heavy metals are also added to cosmetics for various purposes; these heavy metals are very toxic. At low concentrations, some of these heavy metals can cause internal body organ damage. Various abnormalities including cancer, respiratory diseases, intellectual retardation and failure in organ function were reported due to 
metal poisoning (4). According to the National Institute of occupational safety and health (NIOSH) report 1989, around 2983 chemicals are used in cosmetics products. Out of all 884 were found to be toxic, 778 were found to cause acute toxicity, 313 were causing biological mutation, 376 were found to cause skin irritation and eye irritation, 218 were causing reproductivity complications and 148 were carcinogenic. From this data, it became essential to perform toxicity studies on cosmetic products. The primary purpose of toxicity study on cosmetic products/other chemicals is to obtain biological information, required for the estimation of toxic adverse effects of the cosmetics produced after human exposure (3).

\section{Regulatory requirements for cosmetics safety studies}

The U.S. FDA does have an important role in the control and maintenance of cosmetic products in commerce. The FDA can ban, or limit ingredients based on safety concerns, cooperate with manufacturers to undertake countrywide product recalls, enforce warning labels on goods, audit cosmetics manufacturing facilities, issue warning letters, confiscate illicit items, and punish offenders. Subsequently, the FD\&C is a key piece of legislation governing cosmetics sold in the United States. It outlaws the sale of adulterated or misbranded cosmetics and keeps note of any infractions concerning cosmetic ingredients, pollutants, manufacturing, packaging, or shipping and handling (5).

Furthermore, several EU Regulations and Guidance Documents (GDs) relevant to the safety evaluation of industrial chemicals and cosmetic goods define the information required to assess possible detrimental effects of industrial chemicals and cosmetic products on the environment and human health. These rules are as follows (6)-

Regulation (EC) No 1223/2009: of the European Parliament and the Council of 30 November 2009 on cosmetic products.

SCCS/1602/18: Scientific Committee on Consumer Safety (SCCS) Notes of Guidance (NoG) for the Testing of Cosmetic Ingredients and their Safety Evaluation, 10th revision

Besides these regulations, the cosmetic sector is responsible for ensuring that its formulas and products are safe for customers. Cosmetic companies typically achieve this through a variety of mechanisms, including (a) industry standards for good manufacturing practice, (b) the use of ingredients that have undergone safety testing and have been used in cosmetic formulations for decades without evidence of adverse effects, (c) global regulatory standards, and (d) ongoing evaluation and testing of currently used and new ingredients (5).

\section{Approaches for toxicity studies}

There are two approaches for toxicology studiesmechanistic and descriptive. Mechanistic toxicity study is based on the biochemical process by which a toxic effect is produced while the descriptive toxicity study is based on various analytical techniques such as pathology, physiology, and pharmacology. Most of the toxicity studies performed today are descriptive and involve the use of animals. The animals used in the toxicity studies are always killed and examined at the end of the tests. Usually, rabbits, guinea pigs, and albino rats are selected for toxicity studies. The toxicity studies performed on cosmetic products are $(3,7)$ - acute toxicity, skin irritation/corrosion, skin sensitization, repeated dose dermal toxicity, phototoxicity, ocular toxicity, and carcinogenicity.

\section{Acute toxicity}

The goal of acute toxicity studies of cosmetics products is to determine the potential toxicity of chemicals (present in cosmetic products) to humans and other life forms (8). Acute toxicity studies are conducted to determine the potency of toxic chemicals in terms of the median lethal dose (LD50). LD50 is a value that represents the estimated dose causing $50 \%$ of animals' death exposed under fixed conditions of the test (3). Rats are the most commonly used animal for this study. As per directive 92/69/EEC for oral, inhalational and acute toxicity studies at least ten rats (five males and five females) are to be selected and exposed to chemicals at different dose levels (at least three). As per commission directive 93/21/EEC, a chemical agent that produces LD50 at a dose $<25 \mathrm{mg} / \mathrm{kg}$ in a rat exposed by the oral route is classified as "very toxic". A very toxic chemical also produces LD50 at a dose $<50 \mathrm{mg} / \mathrm{kg}$ in rabbits or rats exposed by dermal route or at LC50 at a dose $<0.5 \mathrm{mg} / \mathrm{l}$ in a rat exposed by inhalation for four hours. As per the same directive 93/21/EEC a toxic chemical agent is those that produce LD50 in treated rat between 25 to $200 \mathrm{mg} / \mathrm{kg}$ (oral route), between 50 to $400 / \mathrm{kg}$ (dermal route) and LC50 between 0.25 to $2 \mathrm{mg} / \mathrm{l} / 4 \mathrm{~h}$ (inhalational exposure). Clinical signs of toxicity include bleeding from the mouth, diarrhoea, convulsions, seizures, paralysis and death (Figure 1) (3).

Skin irritation/ corrosion 
Skin irritation is the reversible damage of the skin produced after the application of test substance (chemicals) for up to $4 \mathrm{~h}$, while skin corrosion is the irreversible damage of the skin produced after the application of test substance for up to $4 \mathrm{~h}$, as visible necrosis through the epidermis and into the dermis (9). The goal of estimating the potency of chemicals to induce irritation or corrosion is to evaluate whether information from human experience, animal studies, in-vitro studies or from physiological data provides proof that the chemical is likely to be corrosive or skin, eye, and respiratory irritant (10). Rabbits are most commonly used for this purpose. Two rabbits are selected and exposed to the chemicals for $4 \mathrm{~h}$. Chemicals are exposed to the water-moistened body under semi-occlusive patches. Erythema, scar, and oedema are observed at a predetermined interval of 1, 24, 48, $72 \mathrm{~h}$ after path removal, up to 14 days (Figure 1) (7).

\section{Skin sensitization}

According to OECD test guideline for skin sensitization OECD TG406, "Skin sensitization (allergic contact dermatitis) is an immunological mediated cutaneous reaction to a chemic, substance", and is characterized by pruritic, oedema, erythema, papules or a combination of these in the human (11). The goal of estimating the skin sensitization potency of chemicals is to evaluate whether exposure of the chemical to the human initiates allergic reactions and whether the chemical has a skin sensitization potential when exposed to the animal (10). Skin sensitization is mainly performed on guinea pigs and mice. The mouse ear swelling test (MEST) or local (auricular) lymph node assay (LLNA) was performed on the surface of the mouse ear. When a guinea pig is used for testing, the chemical is applied on the surface or injected under the skin (Figure 1).

\section{Repeated dose dermal toxicity}

As per the OECD TG 410, the dose in a dermal test is the amount of a test substance applied to the skin. The dose is expressed as a weight ( $\mathrm{gm}, \mathrm{mg}$ ) or as the weight of test substance per unit weight of test animal (mg/kg) (12). Repeated dose animal toxicity study provides information on possible health issues, arising from repeated exposure to the chemical by dermal route over a specific period. Rats, guinea pigs or rabbits are used for this study. The test substance is applied daily to several groups of test animals in graduated dose, one dose per group for 21 days/28 days. Animals are observed daily to detect the sign of toxicity, during the period of application (Figure 1) (12).

\section{Phototoxicity}

As per OECD test guideline for phototoxicity OECD TG 432, phototoxicity is defined as a "toxic response from a substance applied to the body which is either elicit or increased (apparent at lower dose level) after subsequent exposure to light or that is induced by skin irritation after systemic administration of substance" (13). Phototoxicity is produced when the skin applied with a chemical/product come in contact with sunlight or UV radiation because chemical forms toxic decomposition products following exposure to the sunlight or UV radiation (14). Guinea pig and mice are most commonly used. The erythemal dose is predetermined, and the product is applied to the skin of the test animal. This is usually done under a patch for a period of $24 \mathrm{~h}$ or $48 \mathrm{~h}$ after a specified time patch is removed and one site irradiated with UV radiation (UV-A and UV-B). after $24 \mathrm{~h}$ of patch removal, both sites (irradiated and non-irradiated) are evaluated and compared with control (Figure 1) (14).

\section{Ocular toxicity studies}

Ocular damage may produce due to accidental or normal contact with the chemicals present in cosmetic products employed for human skincare. The Draize test is used to evaluate qualitative alteration produced in the eyes of examined animals. Most commonly rabbit is used for ocular toxicity. According to the Draize test method, several test animals are applied with test substances in a single dose to one eye. The second untreated eye is used as a control. The degree of irritation produced in the treated eye is evaluated and compared with the control eye (Figure 1) (3).

\section{Carcinogenicity}

The substances which induce tumours (benign or malignant) are known as a carcinogenic substances. When they are ingested, inhaled, injected or dermally applied, they may increase their malignancy or shorten the time of tumour occurrence. Two categories of carcinogens are known: One is genotoxic (induce cancer through interaction with the DNA and induce mutations) and another is non-genotoxic (induce cancer through a mechanism other than DNA damage, like hormonal effects) (1). Most commonly, two species of rodent's mice and rats are used for the carcinogenicity study. Carcinogenicity testing requires more animals than another toxicity testing. At least 100 animals (50 male and 50 female) rodents are used for each of 3 doses. The latency period of tumour formation in rodent's animals is 1 or 2 years. Test substance should be administered 7 days a week for a fraction of life span comparable to the fraction of human life span over which the substance is likely to be used. Generally, the period of dosing should be 24 months for rats and 18 months for mice. 
Observation should include macroscopic changes observed at autopsy and detailed histopathology of organs and tissues (Figure 1) (1).

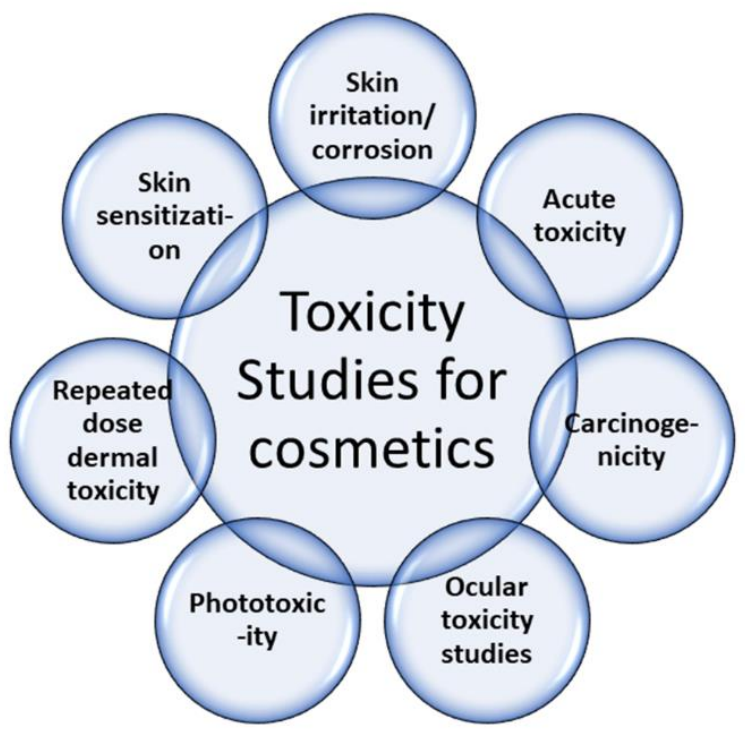

Figure 1. Different approaches for toxicity studies of cosmetic products.

\section{Conclusion}

US FDA states that cosmetics products should not contain harmful substances, but the role of chemicals in cosmetics in modern nations has expanded significantly, that is toxic for the human body and can cause several complications including, cancer, mutation, reproductive toxicity, endocrine disruption etc. NIOSH report 1989, indicates that around 2983 chemicals are used in cosmetic products of which most of which are toxic. Accumulating evidence suggests that it is essential to perform toxicity studies on cosmetic products to obtain biological information, required for the estimation of toxic adverse effects of the cosmetic products produced after human exposure. Two approaches for toxicity studies are there, mechanistic and descriptive. Later is used predominantly that involve use of animals, normally rabbits, guinea pigs, and albino rats. Various descriptive toxicity studies performed are acute toxicity, skin irritation/corrosion, skin sensitization, repeated dose dermal toxicity, phototoxicity, ocular toxicity, and carcinogenicity. The goal and procedure of all the toxicity studies have been discussed in detail.

\section{Contribution of authors}

Both the authors have contributed equally.
I am very thankful to my teachers and colleagues.

\section{Conflicts of interests}

The authors do not have any conflict of interest.

\section{References}

1. Barel AO, Paye M MH. Handbook of cosmetic science and technology. New York: CRC Press; 2014.

2. 1940 US. Federal Food, Drug, and Cosmetic Act 1940 [Internet]. [cited 2021 Dec 10]. Available from: https://www.fda.gov/Cosmetics/GuidanceRe gulation/LawsRegulations/ucm074201.htm

3. N L. Alternative methodologies for the safety evaluation of chemicals in the cosmetic industry. New York: CRC Press;

4. Zulaikha SR, Norkhadijah SI, Praveena SM. Hazardous ingredients in cosmetics and personal care products and health concern: A review. Public Heal Res. 2015;5(1):7-15.

5. Ross G. A perspective on the safety of cosmetic products: a position paper of the American Council on Science and Health. Int J Toxicol. 2006;25(4):269-77.

6. Pistollato F, Madia F, Corvi R, Munn S, Grignard E, Paini A, et al. Current EU regulatory requirements for the assessment of chemicals and cosmetic products: challenges and opportunities for introducing new approach methodologies. Arch Toxicol. 2021;1-31.

7. Chilcott R PS. Principles and practice of skin toxicology. New Jersey: John Wiley \& Sons; 2008.

8. FA B. Principles of toxicology testing. New York: CRC Press; 2013.

9. 2011 U. United Nations Economic Commission for Europe Secretariat. 2011. Globally Harmonized. System of Classification and Labelling of Chemicals (GHS) [Internet]. 2011 [cited 2021 Dec 10]. Available from: https://www.unece.org/fileadmin/DAM/tran s/danger/publi/ghs/ghs_rev04/English/STSGAC10-30-Rev4e.pdf

10. Nielsen E, Ostergaard G LJ. Toxicological risk assessment of chemicals: A practical guide. New York: CRC Press; 2008.

11. 1992 O. Organisation for Economic Cooperation and Development. 1992. OECD guideline for the testing of chemicals, TG406 [Internet]. [cited 2021 Dec 10]. Available from: https://www.oecdilibrary.org/environment/test-no-406-skinsensitisation_9789264070660-en

\section{Acknowledgments}


12. 1981 O. Organisation for Economic Cooperation and Development. 1981. OECD guideline for the testing of chemicals, TG410 [Internet]. [cited $2021 \mathrm{Dec}$ 10]. Available from: https://www.oecdilibrary.org/environment/test-no-410repeated-dose-dermal-toxicity-21-28-daystudy_9789264070745-en

13. 2004 O. Organisation for Economic Cooperation and Development. 2004. OECD guideline for the testing of chemicals, TG432 [Internet]. [cited 2021 Dec 10]. Available from: https://www.oecdilibrary.org/environment/test-no-432-invitro-3t3-nru-phototoxicitytest_9789264071162-en

14. M R. Delivery system handbook for personal care and cosmetic products: technology, applications and formulations. New York: William Andrew; 2005. 